\title{
Pemanfaatan Biomassa Sebagai Inhibitor Organik Pada Baja Aisi 1020 di Universitas Lampung
}

\author{
Rizky Damayanti $^{(1, a)^{*}}$, Pulung Karo-Karo ${ }^{(1, b)}$, Agus Riyanto ${ }^{(1, c)}$ \\ (1) Jurusan Fisika FMIPA Universitas Lampung \\ Jl. Prof. Dr. Soemantri Brodjonegoro 1, Bandar Lampung 35144 \\ ${ }^{(a)}$ Rizkydamayanti999@gmail.com, ${ }^{(b)}$ Pulung@fmipa.unila.ac.id, ${ }^{(c)}$ Arfi2208@gmail.com
}

Diterima (25 Mei 2019), Direvisi (16 Juni 2019)

\begin{abstract}
Research has been conducted on. The utilization of biomassa as an organic inhibitor in AISI 1020 steel at Lampung University. Samples of carbon steel AISI 1020 were immersed in 3\% corrosive medium $\mathrm{HCl}$ without being given and given inhibitors of leaf extract jengkol, salam, ketapang and mango $0.8 \%$ for 4 and 7 days. inhibitors of leaf extract jengkol, salam, ketapang and mango $0.8 \%$ for 4 and 7 days. Calculation of reduction in corrosion rate is carried out by the method of weight loss. The results showed that the addition of Biomasaa inhibitors was effective in reducing the corrosion rate of the samples with the greatest efficiency in the soaking of 7 days of ketapang leaves, which was equal to $74.22 \%$. The results of XRD characterization showed that the phases formed were $\mathrm{Fe}$ and $\mathrm{Fe}_{2} \mathrm{O}_{3}$ in samples coated with inhibitors and in samples soaked without phase inhibitors $\mathrm{Fe}_{2} \mathrm{O}_{3}$ which were corrosion products. The results of SEM characterization showed that the microstructure of the surface of the sample after immersion in the inhibitor contained thin layers overlaying the steel in the sample not coated with the inhibitor, clearly visible cracks and holes indicating that the sample had undergone corrosion.
\end{abstract}

Keywords: Low carbon AISI 1020, corrosion inhibition, HCl, XRD, and SEM-EDS.

\begin{abstract}
Abstrak. Telah dilakukan penelitian tentang.pemanfaatan biomassa sebagai inhibitor organik pada baja AISI 1020 di Universitas Lampung. Sampel baja karbon AISI 1020 direndam dalam medium korosif $\mathrm{HCl}$ 3\% tanpa diberi dan dengan diberi inhibitor ekstrak daun jengkol, salam, ketapang dan mangga $0,8 \%$ selama 4 dan 7 hari. Perhitungan penurunan laju korosi dilakukan dengan metode kehilangan berat. Hasil penelitian menunjukkan bahwa penambahan inhibitor Biomasaa efektif dalam menurunkan laju korosi sampel dengan efisiensi terbesar pada perendaman daun ketapang 7 hari, yaitu sebesar 74,22\%. Hasil karakterisasi XRD memperlihatkan bahwa fasa yang terbentuk adalah $\mathrm{Fe}$ dan $\mathrm{Fe}_{2} \mathrm{O}_{3}$ pada sampel yang di lapisi inhibitor dan pada sampel yang direndam tanpa inhibitor fasa $\mathrm{Fe}_{2} \mathrm{O}_{3}$ yang merupakan produk korosi. Hasil karakterisasi SEM menunjukkan mikro struktur permukaan sampel setelah direndam Inhiblitor terdapat Lapisan-lapisan tipis melapisi baja pada sampel tidak di lapisi inhibitor terlihat jelas retakan dan lubang yang mengindikasikan bahwa sampel telah mengalami korosi
\end{abstract}

Kata kunci: Baja karbon AISI 1020, inhibitor korosi, HCl, XRD, danSEM-EDS

\section{PENDAHULUAN}

Bandar Lampung memiliki lahan hijau berupa hutan sebanyak $7,1 \%$ dan daratan yang nonhutan $91,4 \%$. Luas daratan berupa hutan terdiri dari hutan primer $0,1 \%$, hutan sekunder $6,7 \%$ yang terdiri dari hutan lahan kering dan hutan rawa, serta hutan tanaman seluas $0,3 \%$. Lahan nonhutan lebih didominasi pertanian lahan kering sebesar
$73,5 \%$, sisanya adalah pemukiman sebesar $18 \%$ [1]. Sekitar 73,5\% tumbuhan yang tumbuh dibiarkan begitu saja. Kota Bandar Lampung mempunyai beberapa tempat yang sudah dijadikan Ruang Terbuka Hijau (RTH) di daerah lapangan merah, pasar seni lapangan kalipatru, dan taman kota [2].

Inhibitor korosi dapat didefinisikan sebagai suatu zat yang akan menurunkan serangan korosi. Umumnya inhibitor korosi 
berasal dari senyawa organik dan anorganik [3]. Penggunaan inhibitor dari senyawa anorganik seperti nitrit $\left(\mathrm{NO}_{2}\right)$, kromat $\left(\mathrm{CrO}_{4}\right)$, fosfat $\left(\mathrm{PO}_{4}\right)$ telah banyak digunakan. Senyawa ini adalah senyawa beracun untuk memperoleh inhibitor yang ramah lingkungan oleh karena itu istilah back to nature juga diterapkan dalam penggunanan inhibitor dengan inhibitor organik alami berupa ekstrak daun kering yang mengandung tanin selain pada daun tanin juga terdapat pada akar, kulit, buah, dan batang tumbuhan [4].

Baja merupakan logam yang paling banyak digunakan dalam bidang teknik. Baja dalam pencetakannya biasanya berbentuk plat, lembaran, batangan, pipa dan sebagainya. Baja karbon dapat diklasifikasikan berdasarkan kandungan karbonnya yaitu, baja karbon rendah, sedang, dan tinggi. Baja karbon yang mudah terkorosi tergolong baja karbon rendah [5]. Bagaimanapun bentuk struktur pada logam, logam memiliki kelemahan yaitu mudah terkorosi, sehingga dapat mengakibatkan kegagalan produksi pada komponen industri[6].

Kata korosi berasal dari bahasa latin yaitu corrodere yang artinya perusakan logam atau berkarat [7], penurunan mutu logam akibat reaksi elektrokimia dengan lingkungannya, dan fenomena kimia pada bahan-bahan logam di berbagai macam kondisi lingkungan. Proses korosi tidak dapat dihentikan, namun dapat dicegah dengan banyak cara seperti pelapisan pada permukaan logam, perlindungan katodik, penambahan inhibitor dan lain-lain., penambahan inhibitor cara yang paling efektif untuk mencegah korosi karena dalam penggunaannya memerlukan biaya relatif murah dan prosesnya sederhana [8].

Penelitian tentang inhibitor korosi banyak dilakukan dengan bahan organik

Kemudian panaskan diatas hot plate selama kurang lebih 1 jam hingga warna $\mathrm{N}$ Heksan berubah karena tercampurnya senyawa bahan inhibitor dengan pelarut. seperti daun salam, ekstrak daun kakao [9] dan menggunakan metode maserasi [10].

Pada penelitian ini dibuat ekstrak daun kering didapatkan di Universitas Lampung. Daun kering yang dijadikan inhibitor yaitu daun ketapang, mangga, jengkol, dan salam. Baja yang digunakan adalah baja karbon rendah AISI 1020 dengan konsentrasi inhibitor $8 \mathrm{ml}$ dengan medium korosi larutan $\mathrm{HCl}$ dengan konsentrasi 3\% perendaman 4 dan 7 hari. Tujuan dilakukannya penelitian ini untuk penelitian ini untuk memanfaatkan biomassa berupa daun kering di area Universitas Lampung, serta Melihat laju korosi pada AISI 1020 dengan inhibitor alami dalam medium korosi $\mathrm{HCl}$.

\section{METODE PENELITIAN}

Penelitian ini dilakukan dengan bahan daun jengkol, ketapang, mangga, dan salam sebagai bahan dasar inhibitor, baja karbon rendah (AISI 1020) sebagai sampel pengkorosian, asam klorida $\mathrm{HCl}$ sebagai medium pengkorosi, N-Heksan untuk mengekstrak daun kering yang akan di jadiakn inhibitor dan akuabides untuk membuat larutan $\mathrm{HCl}$.

Metode penelitian yang dilakukan pada penelitian ini terdiri atas beberapa tahap antara lain preparasi sampel baja, pembuatan inhibitor, pembuatan medium korosi, perendaman dengan medium korosi, perhitungan laju korosi serta karakterisasi dan analisis data. Pada jurnal ini telah dilakukan penelitian dengan 9 sampel pada variasi inhibitor dan lama perendaman.

Pembuatan inhibitor menggunakan metode pendingin tegak atau refluks. Masukkan bahan inhibitor dan pelarut ke dalam tabung elenmeyer dan pasang alat ekstraksi pendingin tegak

Saring larutan campuran dengan kertas saring agar dapat dipisahkan antara padatan dan larutan. Dinginkan larutan campuran tersebut dengan cara diangin-anginkan. 
Setelah itu, panaskan kembali pada wadah terbuka agar pelarut N-Heksan dapat menguap. Pada proses ini perlu diperhatikan temperatur maksimum yang dimiliki oleh pelarut. Tahap perendaman dengan inhibitor dilakukan dengan dua waktu 4 dan 7 hari pada masing-masing daun.

Dalam tahap perendaman dengan meium korosi sampel yang digunakan ada sembilan sampel. Dua sampel dilapisi inhibitor daun ketapang, dua sampel inhibitor daun mangga, dua sampel inhibitor daun jengkol, dua sampel inhibitor daun salam, dan satu sampel tanpa dilapisi inhibitor. Waktu perendaman 7 hari dengan medium korosi $\mathrm{HCl} \mathrm{3 \% .}$

Perhitungan laju korosi dilakukan menggunakan metode kehilangan berat yaitu dengan cara menimbang terlebih dahulu massa awal sampel sebelum direndam kemudian menimbang massa akhir sampel setelah direndam. Lalu hasil pengurangan massa awal dengan massa akhir dimasukkan ke dalam perhitungan. Sampel baja yang telah mengalami korosi kemudian diuji menggunakan FTIR untuk mengidentifikasi senyawa kimia, XRD yang bertujuan untuk mengetahui fasa yang terbentuk pada sampel dan SEM yang dilengkapi dengan EDS untuk mengetahui struktur permukaan sampel dan melihat senyawa-senyawa kimia yang ada pada sampel Sampel yang diuji yaitu sampel yang memiliki laju korosi terendah setelah diberi inhibitor pada tiap variasi waktu perendaman. Sedangkan untuk raw material digunakan sampel yang direndam pada hari ke-7.

\section{HASIL DAN PEMBAHASAN}

\section{Laju Korosi Baja Karbon AISI 1020 setelah Perendaman}

Hasil penelitian perendaman baja karbon AISI 1020 yang telah direndam dengan inhibitor daun jengkol, ketapang, salam, dan mangga sebanyak $8 \mathrm{ml}$. Selama 4 dan 7 hari dengan inhibitor dan tanpa inhibitor ditunjukkan pada Tabel 3 . Semakin lama perendaman dengan inhibitor maka laju korosi semakin kecil. Perendaman sampel dengan diberi inhibitor ekstrak daun jengkol, ketapang, salam, dan mangga sebanyak $8 \mathrm{ml}$ menyebabkan penurunan laju korosi sampai pada perendaman 7 hari. Penurunan laju korosi ini disebabkan adanya inhibitor yang melapisi sampel sehingga pengkorosian tidak optimal. Untuk lebih jelas melihat perbandingan laju korosi antara sampel yang direndam dengan diberi inhibitor dan tidak diberi inhibitor terdapat pada grafik yang ditunjukan gambar 1 .

Tabel 3. Data hasil perendaman baja karbon AISI 1020 dalam medium korosif $\mathrm{HCl} 3 \%$.

\begin{tabular}{cccccccccc}
\hline $\begin{array}{c}\text { Kode } \\
\text { Sampel }\end{array}$ & $\begin{array}{c}\mathrm{P} \\
(\mathrm{mm})\end{array}$ & $\begin{array}{c}\mathrm{l} \\
(\mathrm{mm})\end{array}$ & $\begin{array}{c}\mathrm{t} \\
(\mathrm{mm})\end{array}$ & $\begin{array}{c}\mathrm{R} \\
(\mathrm{mm})\end{array}$ & $\begin{array}{c}\mathrm{A} \\
\left(\mathrm{mm}^{2}\right)\end{array}$ & $\begin{array}{c}\text { massa } \\
\text { awal } \\
(\mathrm{mg})\end{array}$ & $\begin{array}{c}\text { massa } \\
\text { akhir }(\mathrm{mg})\end{array}$ & $\begin{array}{c}\Delta \mathrm{m} \\
(\mathrm{mg})\end{array}$ & $\begin{array}{c}\text { Laju Korosi } \\
(\mathrm{mm} / \mathrm{y})\end{array}$ \\
\hline $\mathrm{T}$ & 4,7 & 4,7 & 4,5 & 1,5 & 157,040 & 1,058 & 0,945 & 0,113 & 417,61 \\
$\mathrm{~J} 4$ & 4,7 & 4,6 & 4,6 & 1,5 & 158,002 & 1,041 & 1,000 & 0,041 & 151,50 \\
$\mathrm{~S} 4$ & 4,6 & 4,6 & 4,6 & 1,5 & 156,162 & 0,895 & 0,856 & 0,039 & 146,68 \\
$\mathrm{M} 4$ & 4,6 & 4,8 & 4,6 & 1,5 & 159,842 & 1,063 & 1,022 & 0,041 & 146,33 \\
$\mathrm{~J} 7$ & 4,6 & 4,6 & 4,7 & 1,5 & 158,944 & 1,078 & 1,039 & 0,039 & 144,97 \\
S7 & 4,6 & 4,7 & 4,7 & 1,5 & 160,804 & 1,125 & 1,087 & 0,038 & 139,61 \\
M7 & 4,8 & 4,6 & 4,7 & 1,5 & 162,664 & 1,055 & 1,021 & 0,034 & 122,06 \\
$\mathrm{~K} 4$ & 5,0 & 4,8 & 4,7 & 1,5 & 170,264 & 1,055 & 1,021 & 0,034 & 115,37 \\
$\mathrm{~K} 7$ & 4,9 & 5,0 & 5,0 & 1,5 & 180,970 & 0,989 & 0,956 & 0,033 & 107,66 \\
\hline
\end{tabular}




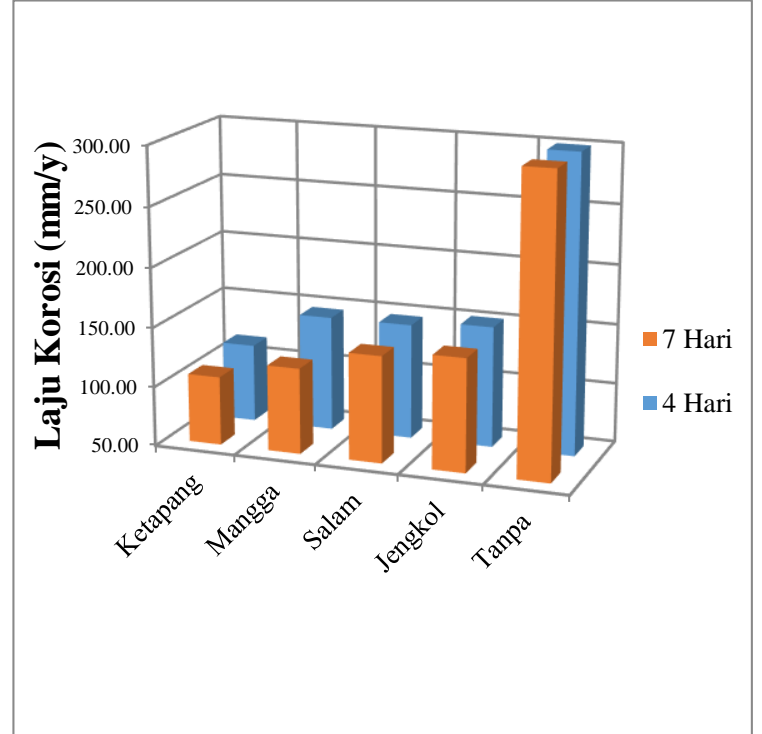

Gambar 1. Hubungan laju korosi baja terhadap inhibitor

Berdasarkan Gambar 1 dapat dilihat bahwa perendaman inhibitor ekstrak daun jengkol, ketapang, salam, dan mangga menyebabkan penurunan laju korosi di tiap waktu perendaman. Dimana pada waktu perendaman 4 hari laju korosi lebih besar dari pada waktu perendaman 7 hari.

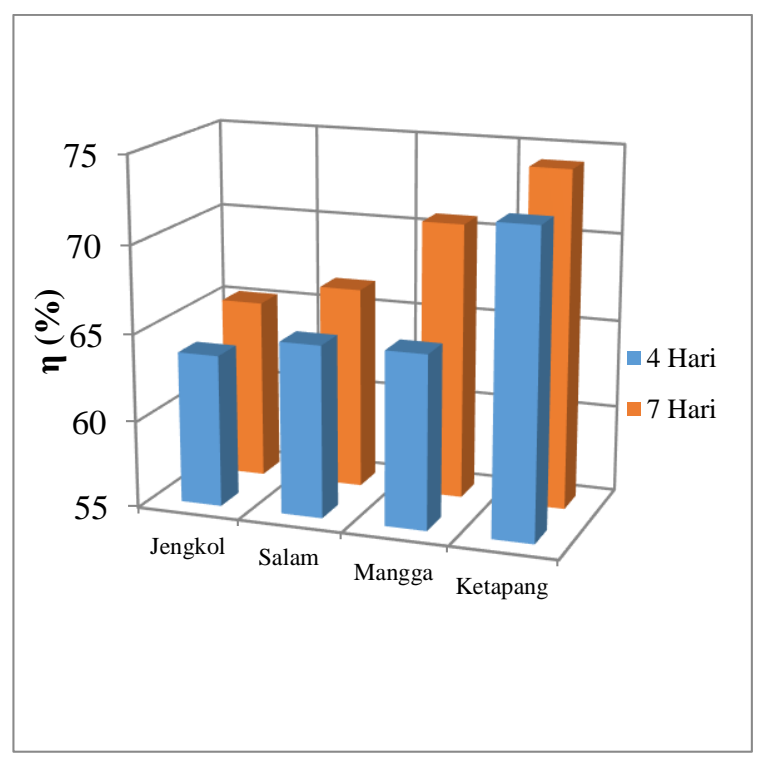

Gambar 2. Hubungan antara efisiensi inhibitor terhadap waktu perendama
Berdasarkan Gambar 1 dapat dilihat bahwa perendaman inhibitor ekstrak daun jengkol, ketapang, salam, dan mangga menyebabkan penurunan laju korosi di tiap waktu perendaman. Dimana pada waktu perendaman 4 hari laju korosi lebih besar dari pada waktu perendaman 7 hari. Nilai laju korosi sampel yang direndam tanpa dilapisi inhibitor sebesar 422,62 $\mathrm{mm} / \mathrm{y}$. Pada perendaman 7 hari laju korosi sampel yang direndam dengan inhibitor daun jengkol sebesar 144,11 $\mathrm{mm} / \mathrm{y}$, daun ketapang sebesar $107,10 \mathrm{~mm} / \mathrm{y}$, daun mangga sebesar $122,76 \mathrm{~mm} / \mathrm{y}$, daun salam sebesar $138,79 \mathrm{~mm} / \mathrm{y}$.

Berdasarkan hasil perbandingan laju korosi sampel tanpa dan dengan diberi inhibitor, maka dapat dilihat efisiensi inhibitor ekstrak daun jengkol, ketapang, salam, dan mangga dalam menghambat laju korosi baja karbon AISI 1020 di tiap waktu perendaman pada Gambar 2.

Berdasarkan Gambar 2 dapat dilihat bahwa efisiensi pada perendaman 7 hari dengan inhibitor ekstrak daun ketapang memiliki efisiensi paling tinggi sebesar $74,77 \%$, ekstrak daun mangga sebesar $70,77 \%$, ekstrak daun salam $66,57 \%$, dan ekstrak daun jengkol memiliki nilai efesiensi terendah sebesar $65,29 \%$. Sesuai dengan referensi tentang pengaruh konsentrasi ekstrak daun ketapang sebagai inhibitor korosi pada baja lunak (mild steel) dalam air laut buatan menghasilkan nilai efisiensi $60,87 \%$ [11].

\section{Analisis Fourier Transform Infra Red (FTIR)}

Hasil analisis FTIR dari daun jengkol, ketapang, salam, dan mangga terdapat kandungan $\mathrm{O}-\mathrm{H}, \mathrm{C}-\mathrm{H}, \mathrm{C}-\mathrm{O}, \mathrm{C}-\mathrm{O}-\mathrm{H}, \mathrm{C}-\mathrm{N}$ dan $\mathrm{C}=\mathrm{C}$. Ditunjukan pada Gambar 3 dan Tabel 2. 


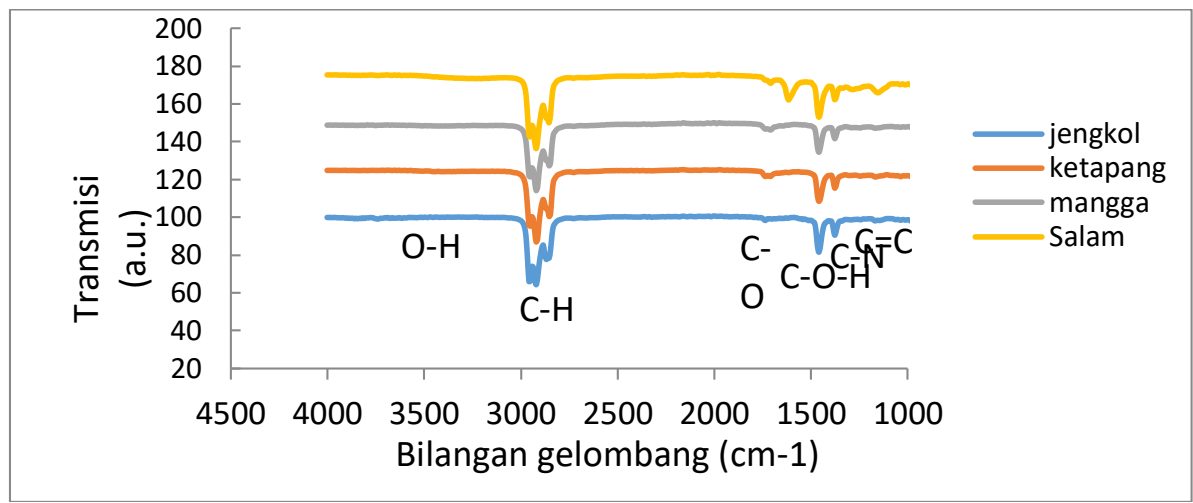

Gambar 3. Spektrum FTIR pada ekstrak biomassa

Tabel 2. Perbandingan hasil analisis spektrum FTIR tanin sampel J7, K7, M7 dan S7

\begin{tabular}{ccccccc}
\hline No. & Tipe Senyawa & $\begin{array}{c}\text { Standar Daerah } \\
\text { Frekuensi }\end{array}$ & $\begin{array}{c}\text { Daun } \\
\text { Jengkol }\end{array}$ & $\begin{array}{c}\text { Daun } \\
\text { Ketapang }\end{array}$ & $\begin{array}{c}\text { Daun } \\
\text { Mangga }\end{array}$ & $\begin{array}{c}\text { Daun } \\
\text { Salam }\end{array}$ \\
\hline 1 & C-H & 2900 & Ada & Ada & Ada & Ada \\
2 & O-H & $3200-3550$ & Ada & Ada & Tidak & Ada \\
3 & C=C & $1610-1680$ & Ada & Ada & Ada & Ada \\
5 & C=O & $1690-1760$ & Ada & Ada & Ada & Ada \\
6 & C-O-H & 1340 & Ada & Ada & Ada & Ada \\
7 & C-N & $1000-1250$ & Ada & Ada & Ada & Ada \\
\hline
\end{tabular}

Hasil analisis ekstrak dari daun jengkol, ketapang, salam, dan mangga ihat pada tabel memiliki kesamaan kandungan pada macam-macam daun, hasil uji fotokimia terdapat beberapa kandungan terdapat saponin, terpenoid, tanin, alkaloid, flavonoid. Ditunjukan pada gugus fungsi FTIR pada masing-masing daun memiliki kesamaan kandungan. Kehadiran beberapa puncak serapan menunjukan adanya kandungan saponin, terpenoid, tanin, alkaloid, flavonoid.

Kandungan saponin pada penelitian ditunjukan pada gugus fungsi $\mathrm{C}-\mathrm{H}, \mathrm{C}-\mathrm{O}$, dan $\mathrm{O}-\mathrm{H}$ [12] Kandungan terpenoid ditunjukan pada gugus fungsi $\mathrm{O}-\mathrm{H}, \mathrm{C}-\mathrm{H}$, $\mathrm{C}=\mathrm{C}, \mathrm{C}-\mathrm{O}, \mathrm{C}=\mathrm{O}$ [13]. Kandungan alkaloid ditunjukan gugus fungsi $\mathrm{O}-\mathrm{H}, \mathrm{C}-\mathrm{N}$ [14] $\mathrm{C}=\mathrm{C}, \mathrm{C}-\mathrm{O}, \mathrm{C}=\mathrm{O}$. Kandungan flavonoid ditunjukan pada gugus fungsi O-H, C-C, $\mathrm{C}=\mathrm{O}, \mathrm{C}-\mathrm{O}, \mathrm{C}-\mathrm{H}$ [15]. Kandungan tanin pada penelitian ditunjukan pada gugus fungsi O-H, C-H, C=O, C-OH [16].

Dari spektrum serapan yang dihasilkan, daun-daun mengandung saponin, terpenoid, tanin, alkaloid, dan flavonoid yang terbukti dari Tabel 2 ada sedikit perbedaan pada daun mangga. Pada analisis daun mangga terdapat tanin dan saponin yang dapat menghambat korosi Berdasarkan hasil uji fotokimia ekstrak metanol daun mangga menunjukkan adanya senyawa golongan alkaloid, flavonoid, stereoid, polifenol, tanin, dan saponin[17]. Pada Tabel 2 menunjukan bahwa kandungan pada daun jengkol, ketapang, salam, dan mangga terdapat senyawa organik yang menghambat korosi yaitu tanin kuat terdapat pada gugus fungsi karakteristik $\mathrm{O}$ $\mathrm{H}, \mathrm{C}-\mathrm{H}, \mathrm{C}=\mathrm{O}, \mathrm{C}=\mathrm{C}$, dan $\mathrm{C}-\mathrm{O}-\mathrm{H}$ [18]. Pada daun mangga tidak memiliki gugus fungsi $\mathrm{O}-\mathrm{H}$. Berdasarkan literatur yang didapat diduga tidak munculnya gugus $-\mathrm{OH}$ yang merupakan ciri tanin di dalam tanaman mangga dikarenakan adanya senyawa lain yang ikut terekstrak oleh pelarut semipolar.

\section{Hasil Analisis X-Ray Diffraction (XRD)}

Karakterisasi dengan XRD dilakukan untuk mengetahui fasa yang terbentuk dalam sampel setelah perendaman. 
Pengujian ini dilakukan pada sampel T, J7, K7, M7, dan S7.

pengujian XRD dengan panjang gelombang yang digunakan sebesar 1,54060 A. Dari hasil XRD sampel yang direndam tanpa inhibitor (T) terdapat 3 puncak yang tajam, sedangkan sampel yang direndam dengan inhibitor daun ketapang (K7) terdapat 4 puncak yang tajam, sampel (J7) terdapat 4 puncak yang tajam, sampel (M7) terdapat yang mengindikasikan terbentuknya fasa kristal. Untuk mengetahui fasa yang terbentuk dilakukan analisis kualitatif terhadap data hasil XRD dengan metode search match analysis atau metode pencocokan data yang diperoleh dengan pangkalan data PDF (Power Diffraction File data base). Software yang digunakan untuk mengidentifikasi adalah PCPDFWIN versi 1.3 JCPSD-ICDD 1997. search match analysis atau pencocokan data sampel diperoleh fasa Fe (besi) dengan data PCPDFWIN nomor 26-1136 dan 060696. Perbandingan antara hasil penelitian sampel J7, K7, M7, S7 dan T dengan program PCPDFWIN ditunjukkan pada tabel.

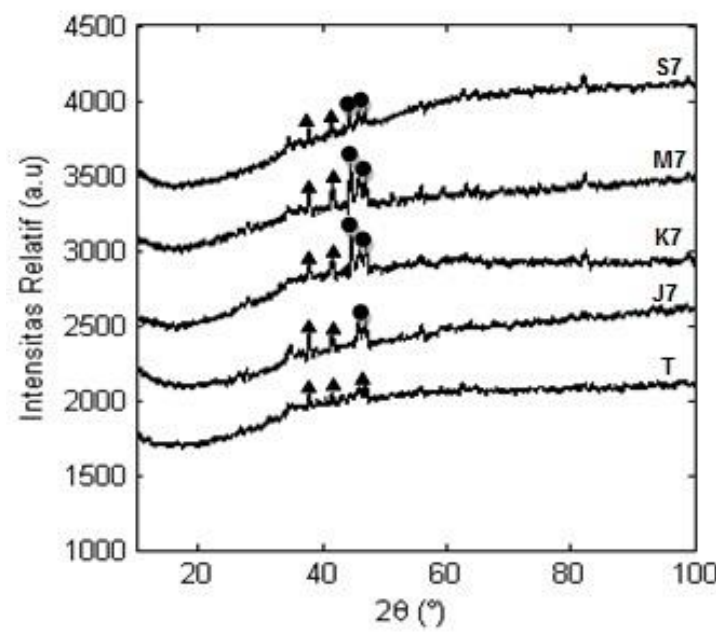

Gambar 4. Difraktogram sampel yang direndam dengan dan tanpa inhibitor selama 7 hari. Legenda: $\bullet=\mathrm{Fe}$ dan $\Delta=\mathrm{Fe}_{2} \mathrm{O}_{3}$
Perbandingan antara hasil penelitian sampel J7 dengan program PCPDFWIN ditunjukkan pada Tabel 3.

Tabel 3. Perbandingan hasil penelitian sampel J7 dengan data PCPDFWIN nomor 26-1136 dan 06-0696.

\begin{tabular}{|c|c|c|c|c|c|}
\hline \multicolumn{2}{|c|}{ Data penelitian } & \multicolumn{2}{|c|}{$\begin{array}{l}\text { Data standar } \\
\text { PCPDFWIN }\end{array}$} & \multirow[t]{2}{*}{$\Delta \mathbf{d}(\AA)$} & \multirow[t]{2}{*}{ Fasa } \\
\hline $2 \theta\left(^{\circ}\right)$ & $\mathrm{d}(\AA)$ & $2 \theta\left(^{\circ}\right)$ & $\mathrm{d}(\AA)$ & & \\
\hline 46,9230 & 1,98136 & 46,110 & 1,9685 & 0,0128 & $\mathrm{Fe}_{2} \mathrm{O}_{3}$ \\
\hline 37,9028 & 2,37382 & 37,280 & 2,4119 & 0,0380 & $\mathrm{Fe}_{2} \mathrm{O}_{3}$ \\
\hline 45,7964 & 1,98136 & 46,110 & 1,9685 & 0,0128 & $\mathrm{Fe}_{2} \mathrm{O}_{3}$ \\
\hline 41,6101 & 2,17049 & 41,927 & 2,1530 & 0,0174 & $\mathrm{Fe}$ \\
\hline
\end{tabular}

Tabel 4. Perbandingan hasil penelitian sampel K7 dengan data PCPDFWIN nomor 06-0696 dan 26-1136

\begin{tabular}{|c|c|c|c|c|c|}
\hline \multicolumn{2}{|c|}{ Data penelitian } & \multicolumn{2}{|c|}{$\begin{array}{l}\text { Data standar } \\
\text { PCPDFWIN }\end{array}$} & \multirow{2}{*}{$\Delta \mathrm{d}(\AA)$} & \multirow[t]{2}{*}{ Fasa } \\
\hline $2 \theta\left(^{\circ}\right)$ & $\mathrm{d}(\AA)$ & $2 \theta\left(^{\circ}\right)$ & $\mathrm{d}(\AA)$ & & \\
\hline 44,7190 & 2,02656 & 44,671 & 2,0268 & 0,0002 & $\mathrm{Fe}$ \\
\hline 47,0420 & 1,93176 & 46,110 & 1,9685 & 0,0367 & $\mathrm{Fe}_{2} \mathrm{O}_{3}$ \\
\hline 45,9434 & 1,97536 & 46,110 & 1,9685 & 0,0068 & $\mathrm{Fe}_{2} \mathrm{O}_{3}$ \\
\hline 41,6088 & 2,17056 & 41,927 & 2,1530 & 0,0175 & $\mathrm{Fe}$ \\
\hline
\end{tabular}

Tabel 5. Perbandingan hasil penelitian sampel M7 dengan data PCPDFWIN nomor 06-0696 dan 26-1136.

\begin{tabular}{|c|c|c|c|c|c|}
\hline \multicolumn{2}{|c|}{ Data penelitian } & \multicolumn{2}{|c|}{$\begin{array}{l}\text { Data standar } \\
\text { PCPDFWIN }\end{array}$} & \multirow{2}{*}{$\Delta \mathrm{d}(\AA)$} & \multirow[t]{2}{*}{ Fasa } \\
\hline $2 \theta\left(^{\circ}\right)$ & $\mathrm{d}(\AA)$ & $2 \theta\left(^{\circ}\right)$ & $\mathrm{d}(\AA)$ & & \\
\hline 44,5682 & 2,03306 & 44,671 & 2,0268 & 0,0123 & $\mathrm{Fe}$ \\
\hline 45,8817 & 1,97787 & 46,110 & 1,9685 & 0,0093 & $\mathrm{Fe}_{2} \mathrm{O}_{3}$ \\
\hline 46,9833 & 1,93404 & 46,110 & 1,9685 & 0,0344 & $\mathrm{Fe}_{2} \mathrm{O}_{3}$ \\
\hline 41,6077 & 2,17061 & 41,927 & 2,1530 & 0,0176 & $\mathrm{Fe}$ \\
\hline
\end{tabular}

Tabel 6. Perbandingan hasil penelitian sampel S7 dengan data PCPDFWIN nomor 06-0696 dan 26-1136.

\begin{tabular}{|c|c|c|c|c|c|}
\hline \multicolumn{2}{|c|}{ Data penelitian } & \multicolumn{2}{|c|}{$\begin{array}{l}\text { Data standar } \\
\text { PCPDFWIN }\end{array}$} & \multirow{2}{*}{$\Delta \mathrm{d}(\AA)$} & \multirow[t]{2}{*}{ Fasa } \\
\hline $2 \theta\left(^{\circ}\right)$ & $\mathrm{d}(\AA)$ & $2 \theta\left(^{\circ}\right)$ & $\mathrm{d}(\AA)$ & & \\
\hline 44,3342 & 2,04325 & 44,671 & 2,0268 & 0,01645 & $\mathrm{Fe}$ \\
\hline 46,9012 & 1,93723 & 46,110 & 1,9685 & 0,03127 & $\mathrm{Fe}_{2} \mathrm{O}_{3}$ \\
\hline 45,9221 & 1,97623 & 46,110 & 1,9685 & 0,00773 & $\mathrm{Fe}_{2} \mathrm{O}_{3}$ \\
\hline 41,5711 & 2,17244 & 41,927 & 2,1530 & 0,01944 & $\mathrm{Fe}$ \\
\hline
\end{tabular}

Tabel 7. Perbandingan hasil penelitian sampel T dengan data PCPDFWIN nomor 06-0696.

\begin{tabular}{|c|c|c|c|c|c|}
\hline \multicolumn{2}{|c|}{ Data penelitian } & \multicolumn{2}{|c|}{$\begin{array}{l}\text { Data standar } \\
\text { PCPDFWIN }\end{array}$} & \multirow[t]{2}{*}{$\Delta \mathbf{d}(\AA)$} & \multirow[t]{2}{*}{ Fasa } \\
\hline $2 \theta\left(^{\circ}\right)$ & $\mathrm{d}(\AA)$ & $2 \theta\left(^{\circ}\right)$ & $\mathrm{d}(\AA)$ & & \\
\hline 37,9092 & 237344 & 37,280 & 2,4119 & 0,03846 & $\mathrm{Fe}_{2} \mathrm{O}_{3}$ \\
\hline & & & & & \\
\hline 45,9317 & 1,97584 & 46,110 & 1,9685 & 0,00734 & $\mathrm{Fe}_{2} \mathrm{O}_{3}$ \\
\hline
\end{tabular}

Analisis Scanning Electron MicroscopyEnergy Dispersive Spectroscopy (SEMEDS) 
Analisis SEM dan EDS dilakukan pada sampel T ditunjukan pada Gambar 5 dan J7,

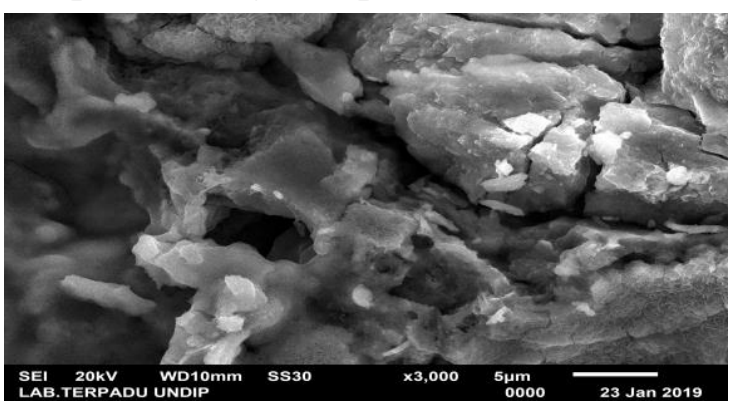

K7, M7, S7 ditunjukan pada Gambar 6.

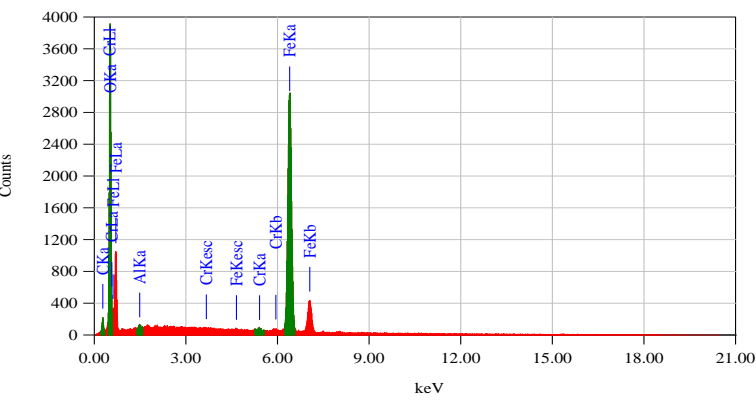

Gambar 5. Hasil SEM (a) Struktur Morfologi (b) EDS sampel T
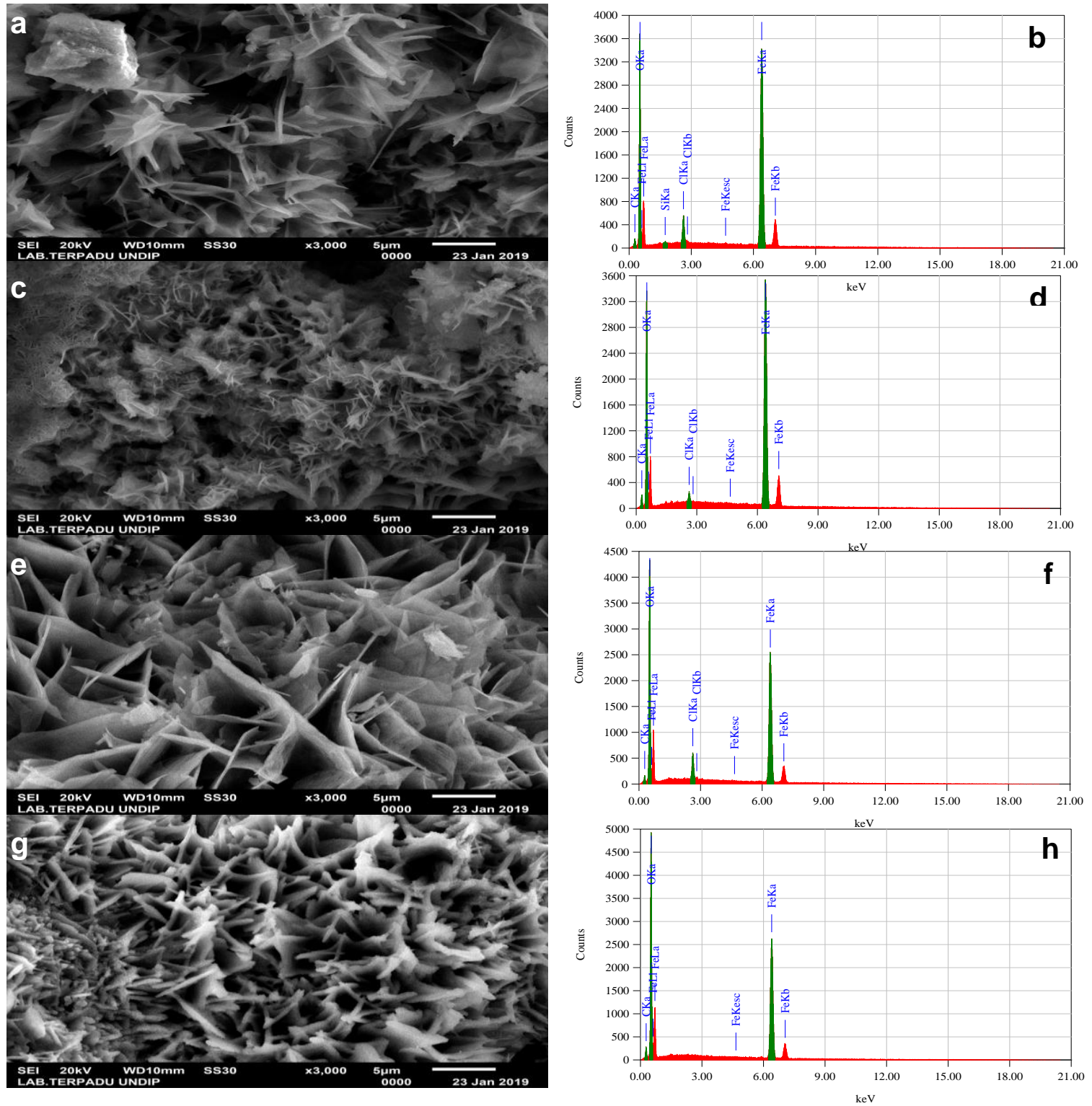

Gambar 6. Hasil SEM sampel (a) J7 (b) EDS J7 (c) K7 (d) EDS K7 (e) M7 (f) EDS M7 (g) S7 (h) EDS S7 dengan perbesaran $3000 \mathrm{x}$ 
Tabel 8. Perbandingan hasil analisis EDS sampel T.

\begin{tabular}{cccc}
\hline & Persentase $(\%)$ & & Persentase(\%) \\
\hline Unsur & $\mathrm{T}$ & Senyawa & $\mathrm{T}$ \\
\hline $\mathrm{C}$ & 10,10 & $\mathrm{C}$ & 3,11 \\
$\mathrm{O}$ & 20,25 & - & - \\
$\mathrm{Al}$ & 0,36 & $\mathrm{Al}_{2} \mathrm{O}_{3}$ & 0,68 \\
$\mathrm{Cl}$ & 0,41 & $\mathrm{Cl}$ & 0,60 \\
$\mathrm{Fe}$ & 68,88 & $\mathrm{FeO}$ & 95,61 \\
\hline
\end{tabular}

Tabel 9. Perbandingan hasil analisis EDS sampel J7, K7, M7 dan S7

\begin{tabular}{|c|c|c|c|c|c|c|c|c|c|}
\hline \multirow{2}{*}{ Unsur } & \multicolumn{4}{|c|}{ Persentase (\%) } & \multirow{2}{*}{ Senyawa } & \multicolumn{4}{|c|}{ Persentase (\%) } \\
\hline & J7 & K7 & M7 & S7 & & J7 & K7 & M7 & S7 \\
\hline $\mathrm{C}$ & 7,51 & 10,64 & 10,21 & 15,42 & $\mathrm{C}$ & 7,51 & 10,64 & 10,21 & 15,42 \\
\hline $\mathrm{O}$ & 20,14 & 19,73 & 19,19 & 18,83 & & & & & \\
\hline $\mathrm{Si}$ & 0,17 & & & & $\mathrm{SiO}_{2}$ & 0,36 & & & \\
\hline $\mathrm{Cl}$ & 2,54 & 0,76 & 5,60 & & $\mathrm{Cl}$ & 2,54 & 0,76 & 3,60 & \\
\hline $\mathrm{Fe}$ & 69,63 & 68,87 & 67,00 & 65,74 & $\mathrm{FeO}$ & 89,58 & 88,60 & 86,19 & 84,58 \\
\hline
\end{tabular}

Produk korosi dapat ditunjukan dengan adanya produk $\mathrm{FeOOOCl}, \mathrm{Fe}_{3} \mathrm{O}_{4}$, $\mathrm{Fe}_{2} \mathrm{O}_{3}$, dan $\mathrm{FeO}$ [18]. Pada XRD menunjukan adanya produk korosi $\mathrm{Fe}_{2} \mathrm{O}_{3}$ dan SEM menunjukan adanya produk koriso FeO. Hasil SEM dan XRD menunjukan dua produk korosi yang berbeda hasil SEM EDS terdeteksi FeO dan pada hasil XRD puncak menunjukan fasa $\mathrm{Fe}_{2} \mathrm{O}_{3}[19]$.

\section{KESIMPULAN}

penurunan laju korosi pada daun ketapang lebih kecil dengan nilai 107,10 mm/y. karakterisasi FTIR biomassa menunjukan adanya kandungan tanin sebagai inhibitor korosi Efisiensi inhibitor daun ketapang bernilai tinggi $74,22 \%$. Hasil karakterisasi XRD memperlihatkan bahwa fasa yang terbentuk pada sampel yang drendam inhibitor adalah $\mathrm{Fe}$ dan $\mathrm{Fe}_{2} \mathrm{O}_{3}$, sedangkan pada sampel tanpa diberi inhibitor fasa yang terbentuk fasa $\mathrm{Fe}_{2} \mathrm{O}_{3}$ saja permukaan sampel setelah direndam inhibitor terdapat lapisan-lapisan tipis yang melapisi baja, pada sampel yang tidak direndam inhibitor terlihat jelas retakan retakan dan lubang pada baja AISI 1020

\section{UCAPAN TERIMAKASIH}

Penulis mengucapkan terima kasih kepada Kepala Laboratorium Fisika Material FMIPA Universitas Lampung.

\section{DAFTAR PUSTAKA}

[1] Anonim, Laporan Status Lingkungan Hidup Daerah Provinsi Lampung. Bandar Lampung, 2009.

[2] Yanti, "Kualitas ruang terbuka hijau publik di Kota Bandar Lampung," Universitas Lampung, 2016.

[3] A. M. Aidil, E. and Shams, "Corrosion inhibition by naturally occurring substance-I. the effect of hibiscus subdariffa (Karkade) extract on the dissolution of $\mathrm{Al}$ and $\mathrm{Zn}$," Corros. Sci., vol. 12, no. 2, pp. 897904, 1972.

[4] Haryati, Potensi dan Peluang Tanaman Obat. Jakarta: Erlangga, 2008.

[5] Sumarji, "Evaluasi Korosi Baja Karbon Rendah ASTM A36 pada 
Lingkungan Atmosferik di Kabupaten Jember," Rotor, vol. 5, pp. 44-51, 2012.

[6] Budianto, K. R. P. Urwantini, B. a T. J. S. Ujitno, J. Babarsari, K. Pos, and Y. Yogyakarta, "Antar Butir Dari Material Baja Tahan Karat Austenitik Setelah Mengalami Proses Pemanasan Material Karat Structure Observation of," Jfn, vol. 3, no. 2, pp. 107-130, 2009.

[7] R. Supardi, Korosi Edisi Pertama. Bandung: Tarsito, 1997.

[8] B. Ilim dan Hermawan, "Study penggunaan ekstrak buah lada, buah pinang dan daun teh sebagai inhibitor korosi baja lunak dalam air laut buatan yang jenuh gas CO2," Pros. Semin. Nas. Sains dan Teknol. II, p. 23, 2008.

[9] N. dan G. Yetri, Y. E., Jamarun, "Corrosion inhibition efficiency of mild steel in hydrocloric acid by adding theobroma cacao peel extract. International Conference on Biological," Chem. Environ. Sci., vol. 27, no. 3, p. 785, 2014.

[10] S. Biantoro, A., Agus, M., dan Boima, "Analisis dan identifikasi senyawa saponin dari daun bidara (Zhizipus mauritania L)," $J$. ITEKIMiA, vol. 2, no. 1, pp. 84-94, 2017.

[11] D. Fath, "Isolasi dan Karakterisasi Senyawa Terpenoid Ekstrak Metanol Akar Pohon Kayu Buta-Buta (Excoecaria agallocha L.," vol. 5, no. 3, pp. 1-6, 2016.

[12] M. T. Budi, E. Fachriyah, and D. Kusrini, "Isolasi, Identifikasi dan Uji Aktifitas Senyawa Alkaloid Daun Binahong (Anredera cordifolia
(Tenore) Steenis)," Chem Info J., vol. 1, no. 1, pp. 196 - 201, 2013.

[13] M. A. Gafur, I. Isa, and N. Bialangi, "ISOLASI DAN IDENTIFIKASI SENYAWA FLAVONOID DARI DAUN JAMBLANG ( Syzygium cumini )," Jur. Kim. Fak. Mipa Univ. Negeri Gorontalo, pp. 1-11, 2012.

[14] I. M. Fathurrahman, N. R, “Artikel tinjauan teknik analisis instrumentasi senyawa tanin," J. Fak. Farm. Univ. Padjajaran, vol. 16, no. 2, pp. 449456, 2018.

[15] D. R. Ningsih, "EKSTRAK DAUN MANGGA (Mangifera indica L.) SEBAGAI ANTIJAMUR TERHADAP JAMUR Candida albicans DAN IDENTIFIKASI GOLONGAN SENYAWANYA," $J$. Kim. Ris., vol. 2, no. 1, p. 61, 2017.

[16] P. P. Sari et al., "Identifikasi dan Uji Aktivitas Senyawa Tanin Dari Ekstrak Daun Trembesi (Samanea saman (Jacq.) Merr) Sebagai Antibakteri Escherichia coli (E. coli)," Kimia, vol. 9, no. 1, pp. 2734, 2015.

[17] I. dan N. B. Gafur, M., Ishak, "Isolasi dan identifikasi senyawa falvonoid dari daun jamblang (Syzgium cumini)," J. Kima FMIPA Univ. Negri Gorontalo, pp. 1-11, 2014.

[18] Ishak, "Analisis Kegagalan Struktur Beton Akibat Korosi Baja Tulangan," vol. 1, no. 1, pp. 70-74, 2011.

[19] B. Di and D. Pencong, "Analisis Mineral Dan Uji Sifat Magnetik Daerah Panas," 2018. 
Damayanti, dkk.: Pemanfaatan Biomassa Sebagai Inhibitor Organik Pada Baja AISI 1020 di Universitas Lampung 